\title{
Conteúdos das vozes de usuários de um Centro de Atenção Psicossocial
}

\author{
Voice content belonging to users \\ at a Psychosocial Care Center
}

Contenidos de las voces de usuarios

de un Centro de Atención Psicosocial

\author{
Luciane Prado Kantorski* \\ Camila Irigonhé Ramos** \\ Cátia Gentile dos Santos ${ }^{* * *+}$ \\ Maria Laura de Oliveira Couto ${ }^{* * * * *}$ \\ Roberta Antunes Machado*****
}

\section{Resumo}

O presente estudo analisou o conteúdo das vozes de usuários de um Centro de Atenção Psicossocial II, localizado na cidade de Pelotas/RS.Trata-se de uma análise documental, realizada por meio da coleta de dados secundários de 389 prontuários de usuários ativos no serviço, dos quais 181 apresentaram o registro de ouvir vozes. A coleta de dados ocorreu entre setembro de $2017 e$ maio de 2018. A partir da análise do registro das falas dos usuários obtidas dos prontuários, foram evidenciadas vozes com conteúdos diversos, como: vozes de comando; vozes de cunho religioso; vozes acompanhadas de outras experiências sensoriais; vozes depreciativas; vozes positivas e vozes neutras. Nos registros pode-se averiguar que os usuários vivenciam as vozes de forma positiva, neutra ou negativa, sendo a identificação dos conteúdos das mesmas um passo importante para auxiliá-los a trabalhar com elas.

Palavras-chave: Ouvidores de vozes; Conteúdo das vozes; Saúde mental.

\footnotetext{
* Universidade Federal de Pelotas, RS, Brasil. E-mail: kantorskiluciane@gmail.com

** Universidade Federal de Pelotas, RS, Brasil..E-mail: mila85@gmail.com

*** Universidade Federal de Pelotas, RS, Brasil..E-mail: catia.gentiles@gmail.com

**** Universidade Federal de Pelotas, RS, Brasil. E-mail: marialauradeoliveiracouto@ gmail.com

***** Instituto Federal de Educação, Ciência e Tecnologia do Rio Grande do Sul, RS,

Brasil. E-mail: roberta.machado@riogrande.ifrs.edu.br
} 


\section{Abstract}

The present study analyzed the content of user voices recorded at a Psychosocial Care Center II, located in the city of Pelotas / RS. This is a documentary analysis, performed by collecting secondary data from 389 medical records of active users in the service, of which 181 had the record of hearing voices. Data collection took place between September 2017 and May 2018. From the analysis of the recordings of the users speech obtained from the medical records, voices with a lot of different content came up, such as: commands; religious voices; voices accompanied by other sensory experiences; derogatory voices; positive voices and neutral voices. The recordings verify that the users experience the voices positively, neutrally or negatively, and the identification of the content is an important step in order to better work with them.

Keywords: Voice hearers; Voice content; Mental Health.

\section{Resumen}

El presente estudio analizó el contenido de las voces de usuarios de un Centro de Atención Psicosocial II, localizado en la ciudad de Pelotas/RS. Se trata de un análisis documental, realizada por medio de la recolección de datos secundarios de 389 prontuarios de usuarios activos en el servicio, de los cuales 181 presentaban el registro de oír voces. La recolección de datos ocurrió entre setiembre de 2017 y mayo de 2018. A partir del análisis del registro del discurso de los usuarios conseguidos en los prontuarios, se evidenciaron voces con contenidos diversos, como: voces de comando; voces de cuño religioso; voces acompañadas de otras experiencias sensoriales; voces despreciativas; voces positivas y voces neutras. En los registros se puede encontrar que los usuarios vivencian las voces de forma positiva, neutra o negativa, siendo la identificación de los contenidos de las mismas un paso importante para auxiliarlos a trabajar con ellas.

Palabras clave: Oyentes de voces; Contenido de las voces; Salud mental.

As explicações para o fenômeno de ouvir vozes são diversas. Quando esse acontecimento foi capturado pela psiquiatria, a interpretação dada foi de um sintoma psiquiátrico,conhecido como alucinação auditiva. No entanto, existe uma outra perspectiva, diferente desta atribuída pela psiquiatria. Trata-se do Movimento Internacional de Ouvidores de Vozes, que considera esse fenômeno como uma experiência singular das pessoas, que não está necessariamente vinculada ao sofrimento ou a um transtorno mental (Fernandes \& Zanello, 2018).

Esse movimento proporciona aos ouvidores(as) que não se sentem amparados(as) pelas abordagens tradicionais uma alternativa para entender 
as vozes. Para tanto, trabalha com uma metodologia que valoriza a escuta das mesmas com a finalidade de conhecer o seu conteúdo, os sentidos atribuídos a elas pelas pessoas que as ouvem, a história de vida dessas pessoas e a relação com o surgimento das vozes, para que elas possam aprender a lidar com esse fato sem causar prejuízo às atividades de vida diária (Corstens, Longden, McCarthy-Jones, Waddingham \& Neil, 2014).

Para os profissionais da saúde, em especial os da saúde mental, compreender o conteúdo das vozes é crucial para o desenvolvimento de um trabalho terapêutico sobre a experiência de ouvir vozes, uma vez que o conteúdo das vozes é o preditor mais relevante sobre as respostas emocionais das pessoas que ouvem vozes em relação a essa experiência, assim como pela procura ou não de ajuda dessas pessoas para lidar com as vozes (Couto, 2018). Uma das primeiras orientações do Movimento é auxiliar os(as) ouvidores(as) a explorar o conteúdo das vozes para que possa ser construída uma relação positiva com elas. Nesse sentido, esse estudo buscou analisar o conteúdo das vozes de usuários/as de um Centro de Atenção Psicossocial II.

\section{METODOLOGIA}

Este estudo consiste na parte qualitativa de uma pesquisa quanti-quali intitulada: Ouvidores de vozes: novas abordagens em saúde mental, aprovada pelo Comitê de Ética em Pesquisa da Faculdade de Medicina da Universidade Federal de Pelotas, sob parecer no 2.201 .138 de 2017. Trata-se de uma análise documental, realizada a partir da coleta de dados secundários do registro dos 389 prontuários de usuários(as) ativos(as) de um Centro de Atenção Psicossocial II, localizado no município de Pelotas/ RS. Destes, 181 apresentaram o registro de ouvir vozes, obtidos a partir da seguinte questão norteadora: Há registro de ouvir vozes?

Em caso positivo, foi descrito pelos(as) coletadores(as) o que constava de registro sobre as vozes. Para este estudo analisou-se os aspectos relacionados aos conteúdos das vozes, tomando como referência os trabalhos de 
Bardin (2011). Com vistas a manter o anonimato dos(as) usuários(as) foi utilizada a letra U seguida de um número natural e o sexo correspondente do(a) usuário(a).

\section{RESULTADOS E DISCUSSÃO}

A partir da análise do registro das falas dos(as) usuários(as), obtidos por meio dos prontuários, foram evidenciadas vozes com conteúdos diversos, como: vozes de comando; de cunho religioso; vozes acompanhadas de outras experiências sensoriais; vozes depreciativas; vozes positivas e vozes neutras. O conteúdo das vozes costuma estar relacionado com a história de vida do(a) ouvidor(a) e com o evento traumático que possa ter desencadeado essa experiência (Andrew, Gray \& Snowden, 2008). Somado a isso, o conteúdo das vozes pode ser considerado um indicador muito importante das reações emocionais do(a) ouvidor(a) frente à experiência (Beavan \& Read, 2010), ou seja, quanto mais intrusivas e amedrontadoras as vozes se apresentam, pior o impacto que elas possuem na qualidade de vida do(a) ouvidor(a). As vozes de comando e de conteúdo negativo são as mais comuns entre os(as) usuários(as) de serviços de saúde mental (Jones, Guy \& Ormrod, 2003).

A seguir descreve-se alguns registros sobre vozes de comando: "Ouve vozes de comando que a mandam matar sua cunhada” (Relato de Atestado do Hospital Psiquiátrico, U1, sexo feminino). "Ouve vozes. Agressão física e automutilação, as vozes de comando sempre mandam ele se agredir” (U2, sexo masculino). "Paciente relata ouvir vozes que afirmam que ela não tem mais o que fazer aqui, que é para se matar” (U3, sexo feminino). "As vozes dizem para ela se matar, que ela não vale nada. 'É voz de homem”' (U4, sexo feminino).

Como exposto nos registros acima, as vozes de comando de cunho negativo podem oferecer riscos significativos, tanto para o(a) ouvidor(a), quanto para as pessoas que convivem com eles(as) quando este(a) não recebe auxílio para lidar com as mesmas. Essas vozes tendem a causar no ouvidor uma crença de que ele é responsável por evitar danos, o que pode se tornar um estressor a mais na sua experiência de ouvir vozes (Ellett et 
al., 2017). Permitir um espaço de fala possibilita que o(a) ouvidor(a) crie estratégias para conviver melhor com essas vozes, e mais importante, que entenda que é ele(a) que comanda as vozes e não o contrário. A partir disso, o(a) ouvidor(a) tem a chance de conviver melhor consigo e com as demais pessoas, diminuindo outros sintomas, tais como isolamento social, inibição da capacidade de realizar as atividades da vida diária, entre outros.

Mesmo que as vozes de comando dos(as) usuários(as) que frequentam os serviços de saúde mental sejam, em sua maioria, negativas, elas também podem dizer para o ouvidor realizar atividades que não conferem riscos, como nos casos a seguir: "Quando não consegue dormir as vozes lhe dão ordens. Atualmente lhe dizem para frequentar a Igreja Católica. Durante o dia não percebe as vozes" (U5,sexo masculino). "Refere hoje que talvez as vozes lhe mandavam sair para que se protegesse já que não confiava nos homens, pai ou mais tarde companheiro. Pensa que quando as vozes lhe mandavam ficar na rua, era porque dentro de casa sentia-se muito insegura" (U6, sexo feminino). "Relata ouvir uma voz 'boa' e uma voz 'ruim' que acha parecida com a voz do seu pai que faleceu há anos. A voz 'boa' diz para não fazer o que a voz 'ruim' manda” (U7, sexo feminino). "Permanecem alucinações auditivas, em alguns momentos as vozes dizem para procurar uma religião. As vozes são de intensidade baixa e só aparecem quando está muito concentrado" (U8, sexo masculino).

Também foram identificados nos registros vozes de conteúdo religioso, que, conforme Rommer e Escher (1993), podem auxiliar o(a) ouvidor(a) a lidar com essa experiência sem se tornar refém da mesma, como relatado nos seguintes registros: "Acha que são vozes de Deus, em função da oração, não percebe as vozes como problema” (U9, sexo masculino). “(...) pede aos espíritos que ajudam a entendê-las, tais como Allan Kardec. Alucinações visuais e auditivas" (U9, sexo feminino). "Paciente refere vozes que lhe falam se vai a igreja (alucinações auditivas)" (U10, sexo feminino). "Compareceu ao grupo, entregue receita, traz novamente a fala de ouvir vozes. Mas que isso é uma questão espiritual. Evita sair de casa por causa destes transtornos. No grupo foi bastante comunicativa" (U11, sexo feminino). 
Um estudo que discutiu o papel da espiritualidade na audição de vozes ressaltou que ela pode contribuir oferecendo uma explicação não clínica e dar sentido à escuta, proporcionar sentimento de controle, conforto, reduzir o sofrimento, aumentar o apoio social e levar a estratégias de enfrentamento das vozes (Mccarthy-Jones, Waegeli \& Watkins, 2013). Outra pesquisa que buscou explorar como o ouvir vozes é conceituado e compreendido pelos ouvidores também trouxe entre os achados que experiências positivas com as vozes derivam de fontes espirituais (Jones et al., 2003).

As experiências religiosas geralmente apresentam efeitos positivos no curso das doenças mentais graves, provocando mudanças na forma de tratar essas questões no âmbito psiquiátrico, em função de mudanças significativas no Manual de Diagnóstico e Estatístico de Transtornos Mentais IV (Koening, 2007). Nesse sentido, a escuta de vozes pode se apresentar de maneira benéfica ao ouvidor. Um estudo realizado com 154 ouvidores identificou quantos conseguiam ouvir vozes de conteúdo positivo, negativo e neutros ou ambíguos. A maioria (46,1\%) relatou ouvir vozes de conteúdo positivo, enquanto $24 \%$ relatou vozes predominantemente negativas e $13,6 \%$ relatou vozes de conteúdo considerado neutro. Destes, $16 \%$ são sons não-verbais, e 14\% são musicais. Os autores chamam atenção para o fato de que são inúmeros os tipos de vozes consideradas neutras pelos ouvidores. No seu próprio estudo, observaram que havia 10 tipos diferentes de vozes consideradas neutras ou ambíguas pelos ouvidores entrevistados, sendo as vozes de chamado a segunda mais prevalente (26\%) (Beavan \& Read, 2010). Alguns exemplos de vozes de chamado estão expostos nos relatos a seguir:

Também refere que ouve vozes que chamam pelo seu nome, às vezes reconhece a voz como do irmão falecido. Diz conviver bem com as vozes. Relata outras vezes que sofre de alucinações auditivas, mas que essas alucinações não incomodam. Sensação que é chamado pelo seu nome enquanto dorme - ocorrendo há dois meses (U16, sexo feminino).

"Por vezes pensa que está sendo chamado, porém sabe que é apenas uma ideia persistente" (U17, sexo masculino).

"Escuta a chamarem na frente de casa (alucinações auditivas). Sempre ouve alguém lhe chamar. Queixa de alucinações auditivas" (U18, sexo feminino). 
Ademais é importante destacar que para o Movimento Internacional de Ouvidores de Vozes a audição das vozes não se limita apenas ao aparelho auditivo, nem a escuta de vozes, pois outros órgãos do sentido também podem ser considerados pelos(as) ouvidores(as), assim como outros tipos de sons (Baker, 2016), como descrevem os apontamentos a seguir: "Refere ouvir vozes; refere que tem um homem com sangue nas mãos e a tem observado" (U12, sexo feminino). "Alucinando, vê pessoas em casa, escuta vozes, diz que cheira a peixe" (U13, sexo feminino). "As vezes refere ouvir vozes e cheiros diferentes" (U14, sexo feminino). "Sente presença da esposa falecida na cama junto com ele" (U15, sexo masculino). "Refere que quer fazer exame neurológico ("exame de cabeça”), devido a zumbido nos ouvidos. Sente dor no meio da cabeça" (U16, sexo feminino). Esses diferentes aspectos que podem compor a audição de vozes são considerados pelos autores da entrevista estruturada Maastricht Interview - ferramenta de pesquisa para extrair informações de pessoas que escutam vozes - na seguinte questão: "Você já teve outra experiência, como visões, estados alterados de percepção, experiências fora do seu corpo, etc? Caso positivo, você poderia descrevê-las?" (Rommer, Escher \& Hage, 2019).

Além disso, existem vozes com conteúdos depreciativos, as quais estão direcionadas a críticas em relação ao(à) próprio(a) ouvidor(a) (Beavan \& Read, 2010), como os apresentados a seguir:

Exame do estado de saúde mental: "vozes". "Fez o uso de medicação para conseguir emagrecer (Dietilpropiona) e então começaram os sintomas psicóticos, ouvia muitas vozes." [...] "Permanece escutando vozes que dizem que a casa está suja, que ela não vale nada.” É voz de homem.» (U19, sexo feminino)

Refere alucinações auditivas. Participa do grupo de ouvidores. Refere ouvir vozes que cochicham, falam baixo, quase de modo incompreensível, porém que ela identifica como de pessoas falando a seu respeito. Pensa que são vozes dos vizinhos falando mal dela. São vozes que falam que ela pode estar sendo traída pelo namorado e que ela está feia. (U20, sexo feminino)

Relata ouvir vozes que estão fora da cabeça, as quais insultam com termos do tipo "nojenta", vozes ameaçadoras (U21, sexo feminino) 
Um dos fatores muito influentes na audição de vozes, no que se refere à prevalência, ao conteúdo e ao sentido das mesmas, é o meio cultural em que o ouvidor está inserido (Laroi et al., 2014). A pesquisa identificou que essa realidade cultural pode ser observada não apenas ao avaliar o conteúdo das vozes de ouvidores de diferentes regiões ou países, mas também em diferentes períodos históricos (Mitchell \& Vierkant, 1989). Nesse estudo, os autores compararam dois grupos de ouvidores que haviam sido hospitalizados no mesmo local, mas em dois períodos diferentes: a década de 1930 e a de 1980 (Mitchell \& Vierkant, 1989). Os registros dos relatos dos ouvidores mostraram que a fonte das vozes era distinta. Nos pacientes da década de 1930, elas eram predominantemente religiosas, descritas como pertencentes a Deus, ao Espírito Santo, e a espíritos, enquanto as vozes dos pacientes da década de 1980 eram seculares e tecnológicas, como vozes do diabo/demônios, médicos, scanner, televisão e rádio.

Da mesma forma, foram observadas diferenças nos conteúdos das vozes. Na década de 1930, as vozes falavam coisas como: “seja uma pessoa melhor ", "viva corretamente ", seja bom e vá para o céu”, "apoie-se no Senhor”, enquanto as da década de 1980 traziam conteúdos mais destrutivos e violentos, como: "mate a si mesmo/outros", "faça coisas perversas" e "ignore a lei". Ou seja, as vozes relatadas na década de 30 falavam mais sobre o desejo de ir para o céu, enquanto que as da década de 80 falavam mais sobre o quanto o ouvidor seria crucificado pelo seus pecados (Mitchell \& Vierkant, 1989). Comparando os resultados do presente estudo com os achados do estudo anterior, percebe-se que o conteúdo depreciativo na atualidade relaciona-se com a maneira que o indivíduo lida com os padrões estéticos, econômicos e culturais, e não mais com aspectos morais (como na década de 1930) ou com a culpa (como na década de 1980).

Existem pessoas que ouvem vozes e têm uma relação positiva com essa experiência, sendo esta vivenciada de forma integrada no cotidiano, sem causar prejuízos ou dificultar tarefas, tornando-se inclusive agradável, como algo a mais na experiência cotidiana ou, até mesmo, como algo que lhes faz companhia e cuja presença é reconfortante (Barros \& Serpa Junior, 2014). Vozes de comando com conteúdo positivo podem ter um impacto benéfico na vida do(a) ouvidor(a), principalmente quando ele(a) as 
reconhece como amigáveis, companheiras e protetoras. As pesquisas sobre ouvidores(as) de vozes demonstram que a diferença entre a população que está inserida nos serviços de saúde mental e aquela que não foi capturada pela psiquiatria está justamente no tipo do conteúdo, nas características e na relação que o(a) ouvidor(a) desenvolve com elas (Laroi et al., 2014; Varese et al, 2016; León-Palacios et al., 2015; Mackinnon, Copolov \& Trauer, 2004).

A predominância de vozes de conteúdo negativo foi evidenciada em outros estudos (Varese et al., 2016; León-Palacios et al., 2015), os quais chamam a atenção para o fato de que ouvidores de vozes usuários de serviço de saúde mental ouvem mais vozes negativas do que os que não fazem uso desses serviços. Esse tipo de conteúdo causa mais angústia e estresse aos ouvidores, fato que pode contribuir para que o mesmo procure ajuda em serviços de saúde mental. Contudo, vozes de conteúdo positivo também podem estar presentes na vida de ouvidores que fazem uso dos serviços, como pode ser visto nos registros a seguir: "No ano de 2017 relatou ouvir vozes do bem, que lhe ajudam, impulsionam e lhe acompanham" (U22, sexo masculino). "Refere que tem ouvido vozes, pai e mãe falecidos, que eles aparecem para protegê-lo de algo que pode acontecer" (U23, sexo masculino).

A forma como as vozes estabelecem relações com o ouvidor são definidas por seus conteúdos (Varese et al., 2016). Além disso, as vozes que facilitam que o ouvidor atinja seus objetivos pessoais produzem sentimentos de prazer, assim como demonstrado pelo relato do U22, que mencionou que as vozes o impulsionam a fazer coisas boas. Pode-se observar que esse ouvidor apresenta uma outra forma de ver e se relacionar com as vozes, diferente da maioria, que relatou vozes negativas, que de alguma forma dificultavam a vida diária, ou ainda vozes neutras, como as de chamado, que não exerciam nenhuma influência significativa em suas atitudes.

Por fim, apesar de ter-se encontrado poucos registros de vozes com conteúdo positivo, é importante destacar que é possível que o ouvidor não apenas conviva com as vozes e crie estratégias para lidar com as mesmas, mas que ele desenvolva uma relação positiva com elas, de companhia, motivação, entre outras. Os(as) usuários(as) do serviço de saúde mental desse estudo que ouvem vozes de conteúdo positivo reforçam que a presença das 
vozes não é um problema. A inabilidade em lidar com as vozes, por outro lado, trata-se de um problema a ser enfrentado por pessoas que frequentam serviços de saúde mental e por pessoas que não frequentam.

\section{CONCLUSÕES}

O presente estudo atingiu seu objetivo ao conseguir evidenciar os diversos conteúdos que as vozes podem possuir. Nos registros pode-se averiguar que os usuários(as) podem vivenciar as vozes de forma positiva, neutra ou negativa. A identificação dos conteúdos das vozes é um passo importante para auxiliá-los(as) a trabalhar com elas. No entanto, esse estudo limitou-se a análise de registros, sendo importante, para outras pesquisas, conhecer esse conteúdo diretamente pelos ouvidores(as).

\section{REFERÊNCIAS}

Andrew, E. M., Gray, N. S., \& Snowden, R. J. (2008). The relationship between trauma and beliefs about hearing voices: a study of psychiatric and non-psychiatric voice hearers. Psychological Medicine, 38(10), 1409- 1417.

Baker, P. (2016). Abordagem de Ouvir Vozes: Treinamento Brasil. Tradução de Lindsei Ferreira Lansky. CENAT - Centro Educacional Novas Abordagens Terapêuticas.

Bardin, L. (2011). Análise de conteúdo. Lisboa: Edições 70.

Barros, O. C., \& Serpa Junior, O. D. (2014). Ouvir vozes: um estudo sobre a troca de experiências em ambiente virtual. Interface (Botucatu), 18(50), 557-569.

Beavan, V., \& Read, J. (2010). Hearing voices and listening to what they say: The importance of voice content in understanding and working with distressing voices. The Journal of Nervous and Mental Disease, 198(3), 201- 205. 
Corstens, D., Longden, E., McCarthy-Jones, S., Waddingham, R \& Neil, T. (2014). Emerging perspectives from the Hearing Voices Movement: implications for research and practice. SchizophreniaBulletin, 4O(supl4), 285-294.

Couto, M. L. O. (2018). Ouvidores de Vozes: uma revisão sobre o sentido e a relação comas vozes. Psicologia USP, 29(3), 418-431.

Ellett, L., Luzon, O., Birchwood, M., Abbas, Z., Harris, A., \& Chadwick, P. (2017). Distress, omnipotence, and responsibility beliefs in command hallucinations. British Journal of Clinical Psychology, 56(3), 303-309.

Fernandes, H. C. D., \& Zanello, V. (2018). Para além da alucinação auditiva como sintoma psiquiátrico. Journal of Nursing and Health, 8(esp), 1-19.

Jones, S., Guy, A., \& Ormrod, J. A. (2003). AQ-methodological study of hearing voices: A preliminary exploration of voice hearers' understanding of their experiences. Psychology and Psychotherapy: Theory, Research and Practice, 76(2), 189-209.

Koening, H. G. (2007). Religião, espiritualidade e transtornos psicóticos. Revista de Psiquiatria Clínica, 34(supl1), 95-104.

Laroi, F., Luhrmann, T. M., Bell, V., Junior, W. A. C., Deshpande, S., Fernyhough, C., Jenkins, J., \& Woods, A. (2014). Culture and Hallucinations: Overview and Future Directions. Schizophrenia Bulletin, 4O(4), 213-220.

León-Palacios, M. G., Úbeda-Gomez, J., Escudero-Pérez, S., BarrosAlbarán, M. D., López-Jiménez, A. M., \& Perona-Garcelán, S. (2015). Auditory verbal hallucinations: can beliefs about voices mediate the relationship patients establish with them and negative affect?. The Spanish Journal of Psychology, 18,E 76.

Mackinnon, A., Copolov, D. L., Trauer, T. (2004). Factors associated with compliance and resistance to command hallucinations. The Journal of Nervous and Mental Disease, 192(5), 357 - 362.

Mccarthy-Jones, S., Waegeli, A., \& Watkins, J. (2013). Spirituality and hearing voices: considering the relation. Psychosis, 5(3), 247-258. 
Mitchell, J., \& Vierkant, A. D. (1989). Delusions and hallucinations as a reflection of the subcultural milieu among psychotic patients of the 1930s and 1980s. The Journal of Psychology, 123, 269-274.

Rommer, M., \& Escher, S. (1993). Accepting voices. London: MIND publications.

Rommer, M., Escher, S., \& Hage, P. (2019). Maastricht Interview for adults. Recuperado de http://www.hearingvoices.org.nz.

Varese, F., Morrison, A. P., Beck, R., Heffernan, S., Law, H., \& Bentall, R. P. (2016). Experiential avoidance and appraisals of voices as predictors of voice-related distress. British Journal of Clinical Psychology, 55(3), 320-331.

Recebido em 10/09/2019

Aceito em 20/04/2020 